\title{
Pursuing a post-Paris plan
}

\author{
After the success of last December's climate negotiations, politicians and researchers are starting to eye \\ a 'post-Paris' agenda.
}

More than 100 days after 196 world leaders did the improbable and signed an international deal in Paris to cut greenhouse gas emissions, there remains much to sort out.

To start, the Paris Agreement has to be ratified. It seems policymakers learned from past hiccups not only when formulating the Agreement, but also when designing the ratification process. Unlike previous deals, the Paris Agreement requires 55 countries representing at least $55 \%$ of global emissions to ratify the deal if it is to come into force by 2020 .

The ball is already rolling. Fiji was the first to ratify in February, with Palau soon following suit. The Marshall Islands in March completed the Pacific Island vanguard. Perhaps most significantly, the US and China - making something of a habit of joint climate-related announcements declared that they would both take steps to approve the Agreement "as early as possible [in 2016]". Those two countries account for around $40 \%$ of global emissions.

Although political progress continues apace, the implications of the Paris Agreement for research remain somewhat less certain. Contained within the deal is a request from the UNFCCC for the IPCC to produce a special report regarding the impacts of, and pathways to, $1.5^{\circ} \mathrm{C}$ of warming. Academics are divided on the best response. For instance, Mike Hulme (Nature Clim. Change 6, 222-224; 2016) recently argued that the request represents a legitimate opportunity for the IPCC to provide the best available scientific advice to policymakers, while at the same time working to reform the mechanisms of science-policy interaction. Reto Knutti and colleagues (Nature Geosci. 9, 13-18; 2016) suggest that whether the world aims for $1.5^{\circ} \mathrm{C}$ or $2{ }^{\circ} \mathrm{C}$ is something of a moot point, however, as the mitigation actions for both pathways look largely the same. Glen Peters
(Nature Clim. Change http://doi.org/bd6v; 2016) argues that the utility of any special report lies in resolving fundamental uncertainties around the $1.5^{\circ} \mathrm{C}$ 'aspiration', rather than fixating on unachievable mitigation pathways.

The IPCC met in April to discuss, among other things, how to handle the UNFCCC's request. Their decision on whether to proceed with the report is symbolically important, as it indicates what role the IPCC anticipates playing in the policymaking process.

That decision is just a starting point, however. Other avenues of research - from scrutinizing countries' intended nationally determined contributions, to investigations into overshoot and rebound, analysis of attribution relating to loss and damage, and many more - will continue to emerge from the Paris Agreement. Nature Climate Change hopes to represent each strand in the coming months and years.

\section{The devil is in the deep tail}

\author{
Economic research is starting to pay increasing attention to the social impacts of significant (if less \\ likely) climatic events.
}

In order to make informed, risk-based decisions, policymakers must have information not only on probable events, but also on the worst (if less probable) scenarios. The interconnectedness of climatic systems makes assessing the social impacts of those events tricky, however.

Two studies in this issue use the concept of 'tipping points' to assess optimal policy responses in the face of uncertainty around the nature and timing of extreme events, and the way they interact.

Derek Lemoine and Christian Traeger (see page 514) analyse the impact of three different tipping points occurring at unknown thresholds. They show that because the occurrence of one climatic tipping point affects the chances of another happening, this creates a 'domino effect', almost doubling today's optimal carbon price. Yongyang Cai, Timothy Lenton and
Thomas Lontzek model the impact of five tipping points (see page 520), and suggest the interaction of these impacts means the social cost of carbon increases as much as eightfold.

Although not an entirely new endeavour - some leading integrated assessment models have already adjusted their calculations to account for the impact of such 'discontinuities' - both pieces of research suggest the same course of action: risk-averse policymakers should support efforts to significantly curb greenhouse gas emissions in the short term (see the News \& Views by Frederick van der Ploeg on page 442).

Such a risk-averse strategy also emerges as a sensible option when looking at impacts beyond tipping points. Research by Simon Dietz and colleagues offers a first estimate of the potential impact of climate change on the value of financial assets (Nature Clim. Change http://doi.org/bd4s; 2016). They suggest that around $1.8 \%$ or US $\$ 2.5$ trillion of the world's financial assets could be at risk from businessas-usual emissions. But the devil is in the detail (or the tail of the probability distribution, in this instance). At the 99th percentile, the value of assets at risk is closer to US\$24 trillion, illustrating the potential scale of the risk.

This suggests not only that investors should see climate change as a serious threat to wealth (see S. Fuss, Nature Clim. Change http://doi.org/bd4t; 2016), but that they must decide exactly how much risk they are willing to bear. This holds for decision-makers across the board: whatever happens, they have been warned that it was at least a possibility, at a given probability. 